\title{
Using Thermal Neutron Imaging in Forest Products Research ${ }^{\dagger}$
}

\author{
Nayomi Z. Plaza 1,*, Rebecca E. Ibach ${ }^{1}$, Laura E. Hasburgh ${ }^{2}$ and Michael Taylor ${ }^{3}$ \\ 1 Forest Biopolymers Science and Engineering, Forest Products Laboratory, USDA Forest Service, One \\ Gifford Pinchot Dr., Madison, WI 53726, USA; rebecca.e.ibach@usda.gov \\ 2 Building and Fire Sciences, Forest Products Laboratory, USDA Forest Service, One Gifford Pinchot Dr., \\ Madison, WI 53726, USA; laura.e.hasburgh@usda.gov \\ 3 Phoenix Neutron Imaging Center, 5125 Lacy Rd, Fitchburg, WI 53711, USA; michael.taylor@phoenixwi.com \\ * Correspondence: nayomi.plazarodriguez@usda.gov \\ + Presented at the 1st International Electronic Conference on Forests - Forests for a Better Future: \\ Sustainability, Innovation, Interdisciplinarity, 15-30 November 2020; Available online: https://iecf2020.scifo- \\ rum.net.
}

Citation: Plaza, N.Z.; Ibach, R.E.; Hasburgh, L.E.; Taylor, M. Using Thermal Neutron Imaging in Forest Products Research. Environ. Sci. Proc. 2021, 3, 92. https://doi.org/10.3390/ IECF2020-08082

Academic Editors: Angela Lo Monaco, Cate Macinnis-Ng and Om P. Rajora

Published: 13 November 2020

Publisher's Note: MDPI stays neutral with regard to jurisdictional claims in published maps and institutional affiliations.

Copyright: $\odot 2020$ by the authors. Licensee MDPI, Basel, Switzerland. This article is an open access article distributed under the terms and conditions of the Creative Commons Attribution (CC BY) license (http://creativecommons.org/licenses/by/4.0/)

\begin{abstract}
Neutron imaging is a nondestructive evaluation technique with enhanced hydrogen sensitivity that allows researchers to monitor water content and transport in materials. In lignocellulosic research, this technique has typically been used to measure changes in moisture content, water transport and even local changes in the density of wood. Yet, studies looking into the combined effects of moisture-uptake, chemical modifications and thermal degradation are still lacking. This is perhaps due to the inherent limited availability of these instruments and their lesser spatial resolution compared to X-ray imaging. While recent advances in detector technology and neutron production have led to continued improvements in both instrument availability and spatial resolution, the technique remains underutilized in forest products research. Here, we used thermal neutron imaging to measure differences in the attenuation of the neutron beam due to acetylation in both solid wood samples and wood-plastic composite samples, as well as a thermally degraded wood sample. Our results show that moisture plays a key role in the contrast. Moreover, we showed that the attenuation coefficient is particularly sensitive to changes in density and/or local hydrogen content caused by thermal degradation of the wood polymers.
\end{abstract}

Keywords: neutron imaging; radiography; thermal degradation; acetylated wood

\section{Introduction}

There is an increased interest in the use of forest products for construction beyond low-rise, residential purposes due to their sustainability and ability to sequester carbon [1]. Yet, when used outdoors these products are subject to various environmental conditions that can compromise their long-term durability. Nondestructive evaluation that can provide insights into how forest products' material properties are affected by these conditions could be valuable in accelerating the development of effective and environmentally friendly protection systems. However, characterizing wood and other lignocellulosic materials is difficult because of their inherently complex chemistry and hierarchical structure. Moreover, the contrast between the polymeric constituents is often poor.

Neutron-based technologies are uniquely suited to probe lignocellulosic materials because neutrons interact with the sample nuclei and have no dependence with the atomic number [2]. Neutron imaging (also referred to as neutron radiography in the literature) can be used to nondestructively study the bulk distribution of moisture and other hydrogen-rich components with sub-mm spatial resolution depending on the source and detector technology used [3]. Thus, this technique is becoming an important tool in cultural heritage research of ancient artifacts including pottery, metal-clad statues and even fos- 
silized woods [3,4]. Its high sensitivity to hydrogen content makes thermal neutron imaging (TNI) a powerful tool to evaluate how forest products are chemically modified as well as how they degrade. Despite its potential, the technique has not been widely used in wood and forest products research. The limited existing research has focused on investigating moisture uptake and water transport effects in various wood-based products [5-8], including wood-plastic composites [9]. While, others have used the technique to measure local density variations across growth rings [10]. More recently, cold neutron imaging has been used to monitor the in situ changes caused by thermal modification [11] and pyrolysis of wood [12].

In this manuscript, we give an overview on the use of TNI in a variety of forest products including unmodified and acetylated solid wood and wood-plastic composites, as well as thermally degraded wood. These materials were selected because of their use as outdoor products that need to withstand the elements. Acetylation was selected because it is a commercial nontoxic wood modification that is used for improving the decay resistance of these products. We also studied a sample exhibiting a thermal degradation profile to determine the potential of TNI in detecting degradation-induced variances within a sample. Our results show that, by carefully controlling the moisture content in these samples, the image contrast can be further improved to detect localized defects. Furthermore, our data supports that TNI can be a powerful tool to assess degradation in terms of decreased density or hydrogen content, since these directly impact the measured attenuation coefficient. Thus, TNI may be particularly useful in assessing the efficacy of wood modification and other protection treatments meant to prevent decay and degradation.

\section{Materials and Methods}

Acetylated wood sample: Southern pine (Pinus spp.) sapwood blocks ( $25.4 \mathrm{~mm}$ wide $\times 25.4 \mathrm{~mm}$ long $\times 6.4 \mathrm{~mm}$ thick) were cut and dried at $105^{\circ} \mathrm{C}$ in a forced draft oven for 24 $\mathrm{h}$ and then weighed. Acetylation was performed by immersing the blocks in acetic anhydride at $120{ }^{\circ} \mathrm{C}$ for $240 \mathrm{~min}$ in a glass reactor [13]. The acetylated sample was waterleached for 14 days to remove any residues (acetic acid by-product) from the modification. The acetylation led to an average weight percent gain of $19.8 \%$ as determined from its original oven-dried weight.

Thermally degraded wood sample: Thin sections $(4 \mathrm{~mm}$ ) of a Douglas fir (Pseudotsuga menziesii) specimen were cut from a thermally degraded wood sample. The thermal degradation occurred by exposing the radial surface of an oven-dried Douglas fir wood specimen $(100 \mathrm{~mm} \times 100 \times 21 \mathrm{~mm})$ to a constant heat flux of $50 \mathrm{~kW} / \mathrm{m}^{2}$ using a cone calorimeter (FTT iCone Mini, East Grinstead, West Sussex, UK) without piloted ignition. Once the temperature of the bottom surface reached $100^{\circ} \mathrm{C}$, the sample was removed from the cone calorimeter, and the fire on the top surface was extinguished with water. Then, the specimen was cut along the transverse plane into $4 \mathrm{~mm}$ thick sections to expose the changes caused by the thermal degradation across various growth rings.

Wood-plastic composites (WPCs): The WPCs were made from high-density polyethylene (HDPE) from reprocessed milk bottles (Muehlstein and Co., Inc., Roswell, GA, USA), and ponderosa pine (Pinus ponderosa) flour (AWF-4020), nominal 40 mesh (420 $\mu \mathrm{m}$ ), from American Wood Fiber (Schofield, Wisconsin). Adding 6 or $7.8 \%$ TPW-113 lubricant from Struktol Company of America (Stow, Ohio) helped prevent tearing of the material as it exited the die [14]. To produce the WPCs, the HDPE was melted, and blended with the wood flour and the lubricant. Then, the material was extruded thru a die into rectangular specimens $(3 \mathrm{~mm}$ thick $\times 13 \mathrm{~mm}$ wide $\times 76 \mathrm{~mm}$ long). For the acetylated WPCs, the wood flour was oven dried and then boiled in acetic anhydride in a 1-L glass reactor for 4 $\mathrm{h}$ to increase its acetyl content. The treated flour was washed and oven dried, and its weight gain percentage (WPG) was calculated. Percentage acetyl content was determined using anion exchange high-performance liquid chromatography with a suppressed conductivity detector, following a previously described methodology [15]. The average acetyl 
content of the acetylated flour was $22.65 \% \pm 0.01$ (average of 24 batches) while the unmodified flour was $1.95 \% \pm 0.00$ (average of 4 samples.)

Neutron imaging: Experiments were conducted at one of the thermal neutron beamlines available at the Phoenix Neutron Imaging Center. Two-dimensional neutron radiography using conventional X-ray films in contact with high-resolution neutron conversion screens were used to measure the effects of moisture content and local density variations in the test specimens. First, all the samples were imaged dry at the beamline room conditions. The samples were fastened onto the plates using $\mathrm{Al}$ tape, exposed to thermal neutrons for $1.5 \mathrm{~h}$ and were safe to handle immediately afterward. A week later, the same samples were soaked in water for over $24 \mathrm{~h}$, patted dry to remove the excess water and wrapped in aluminum foil to keep their moisture content stable. Then, the wrapped samples were imaged again using the thermal neutron beam. The increase in water content due to the immersion was determined by comparing the weight of the air-dried samples and the unsealed wet samples at the end of the experiment. The average thickness of the dry and wet samples was also measured. The films were developed in a dark room and digitized for quantitative analysis. The digitized images were first flattened along the Zaxis. Then, these corrected images were imported into ImageJ [16] where linear profiles were drawn over regions of interest to calculate the macroscopic attenuation coefficient, $\Sigma$, for each sample based on Beer-Lamberts law (1)

$$
\Sigma=\frac{\ln \left(\frac{I_{0}}{I}\right)}{d}
$$

where $I_{0}$ is the incident beam intensity, $I$ is the transmitted beam intensity and $d$ is the sample thickness. For the wood samples, linear profiles were drawn across several growth rings, and the transmitted intensity values were averaged over at least five rings to calculate the attenuation coefficient, $\Sigma$, based on Equation (1). For the WPCs, linear profiles were drawn along the length of the samples, and attenuation coefficients were calculated based on the average transmitted beam measured. All image processing and analysis was performed using the ImageJ tools in FIJI [17].

\section{Results and Discussion}

The neutron radiographs obtained from the unmodified and acetylated wood samples in both dry and wet conditions are shown in Figure 1. The weight of both the unmodified and the acetylated samples increased considerably after being immersed over $24 \mathrm{~h}$ in water $(112 \%$, and $87 \%$ with respect to their dry weights, respectively). The contrast between the less-dense earlywood bands and the dense latewood bands was very high for all dry samples (Figure 1a,c), however, increasing the moisture content of the samples significantly reduced this contrast. Interestingly, unlike other imaging techniques such as $\mathrm{X}$-ray computed tomography (XCT) or clinical magnetic resonance imaging (MRI), here the rings were still distinguishable in both dry and wet conditions [18].

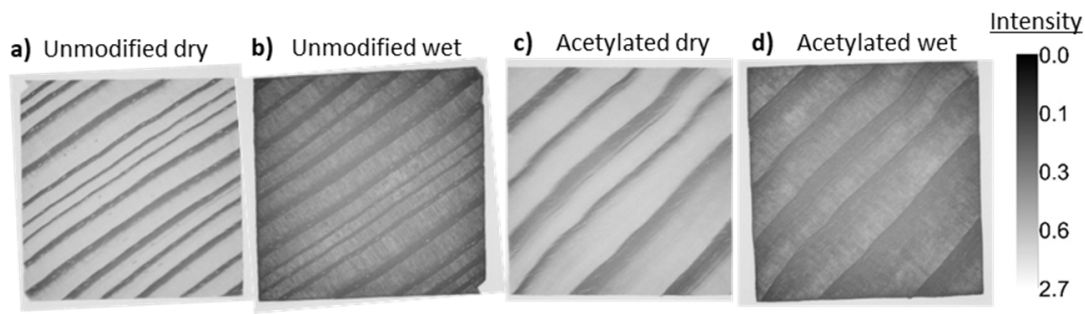

Figure 1. Digitized neutron radiographs obtained from unmodified wood at (a) dry and (b) wet conditions, and acetylated wood at (c) dry and (d) wet conditions.

Quantitative analysis revealed that the increase of moisture content in these samples increased their attenuation coefficient (Table 1). This was most noticeable in the less dense 
earlywood regions probably because increasing the moisture content there led to a larger increase in the local apparent density. While the natural variability of wood likely contributes to the spread observed in the calculated attenuation coefficients, it should be noted that implementing normalization routines to account for deviations to the Beer-Lamberts law, such as a black body bias correction, can improve considerably the reproducibility and accuracy of the measured attenuation coefficient in hydrogenous samples [19]. Thus, future experiments on wood samples may benefit from the use of postprocessing normalization algorithms.

Table 1. Average macroscopic attenuation coefficients of the unmodified and acetylated wood in dry and wet conditions. Standard deviations are shown in parenthesis.

\begin{tabular}{ccc}
\hline \multirow{2}{*}{ Sample } & \multicolumn{2}{c}{$\boldsymbol{\Sigma} \mathbf{( 1 / \mathbf { c m } )}$} \\
\cline { 2 - 3 } & Dry & Wet \\
\hline \multirow{2}{*}{ Unmodified Wood } & $0.86(0.15)^{1}$ & $0.92(0.33)^{1}$ \\
Acetylated Wood (20\% WPG) & $0.15(0.04)^{2}$ & $0.63(0.21)^{2}$ \\
& $0.71(0.16)^{1}$ & $0.75(0.21)^{1}$ \\
& $0.16(0.07)^{2}$ & $0.60(0.21)^{2}$ \\
\hline
\end{tabular}

${ }^{1}$ Latewood. ${ }^{2}$ Earlywood.

The radiographs obtained by imaging unmodified and acetylated WPCs in dry and wet condition are shown in Figure 2. Interestingly, for the WPCs we did not observe significant differences between the acetylated and the unmodified samples. Soaking these samples in water only increased their water content slightly ( $5 \%$ for the unmodified sample and $1 \%$ for the acetylated one compared to their dry weights). Therefore, it is not surprising that this small change did not yield observable differences. Future experiments with increased soaking times could increase the moisture content in these samples and provide new insights.

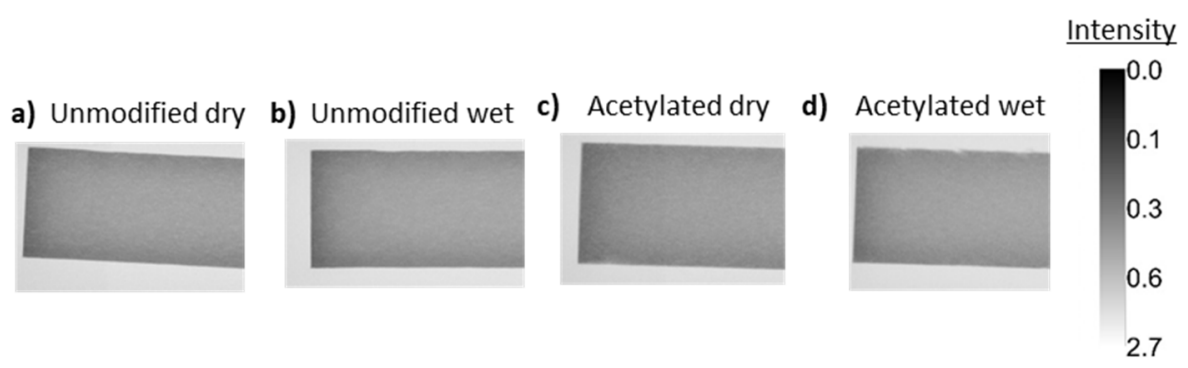

Figure 2. Digitized neutron radiographs of WPCs made with unmodified wood flour imaged (a) dry and (b) wet, and WPCs made with acetylated wood flour imaged (c) dry and (d) wet.

Quantitative image analysis along the length of the WPCs revealed that even though no significant differences were detected between the dry and wet samples, all samples were significantly more attenuated near the surfaces (Table 2). Possible explanations for this behavior include: the presence of a gradient in the materials' properties due to the extrusion process used to fabricate the samples and/or that the wood fibers on the surface are more accessible to moisture [20] and thus more attenuated than the interior of the sample. However, considering the magnitude of the differences observed in our neutron images, further experiments and postprocessing analysis that include black body bias corrections are likely needed to further confirm the presence of an attenuation gradient near the surfaces. 
Table 2. Average macroscopic attenuation coefficients of the unmodified and acetylated WPCs in dry and wet conditions. Standard deviations are shown in parenthesis.

\begin{tabular}{ccc}
\hline \multirow{2}{*}{ Sample } & \multicolumn{2}{c}{$\boldsymbol{\Sigma}(\mathbf{1} / \mathbf{c m})$} \\
\cline { 2 - 3 } & Dry & Wet \\
\hline \multirow{2}{*}{ Unmodified WPC } & $1.18(0.04)^{1}$ & $1.06(0.20)^{1}$ \\
& $0.84(0.07)^{2}$ & $0.77(0.06)^{2}$ \\
\hline \multirow{2}{*}{ Acetylated WPC } & $1.31(0.24)^{1}$ & $1.12(0.20)^{1}$ \\
& $0.85(0.07)^{2}$ & $0.79(0.05)^{2}$ \\
\hline
\end{tabular}

${ }^{1}$ Surface regions. ${ }^{2}$ Nonsurface areas.

Soaking the thermally degraded sample in water over $24 \mathrm{~h}$ increased its weight though not as much as the unmodified sample ( $60 \%$ vs. $112 \%$, respectively). For the thermally degraded wood sample we observed that increasing the moisture content of the sample improved the contrast considerably and revealed the presence of cracks and defects that were otherwise indistinguishable (Figure 3a,b). The changes in the attenuation coefficient along the thermal degradation profile in the imaged dry sample are plotted in Figure 3c. Interestingly, despite the low contrast in the dry sample, we still were able to observe a significant decrease in the attenuation coefficient with increased thermal degradation. Given that for wood, it is estimated that hydrogen accounts for nearly $90 \%$ of the total attenuation [10,12], regardless of the neutron incident energy, it is likely that most of the decrease observed corresponds to a loss in the overall hydrogen content of the thermally degraded wood polymers. Considering that the attenuation is inherently dependent on the material's density it is conceivable that decreases in the wood's density as it is thermally degraded also contribute to attenuation loss.
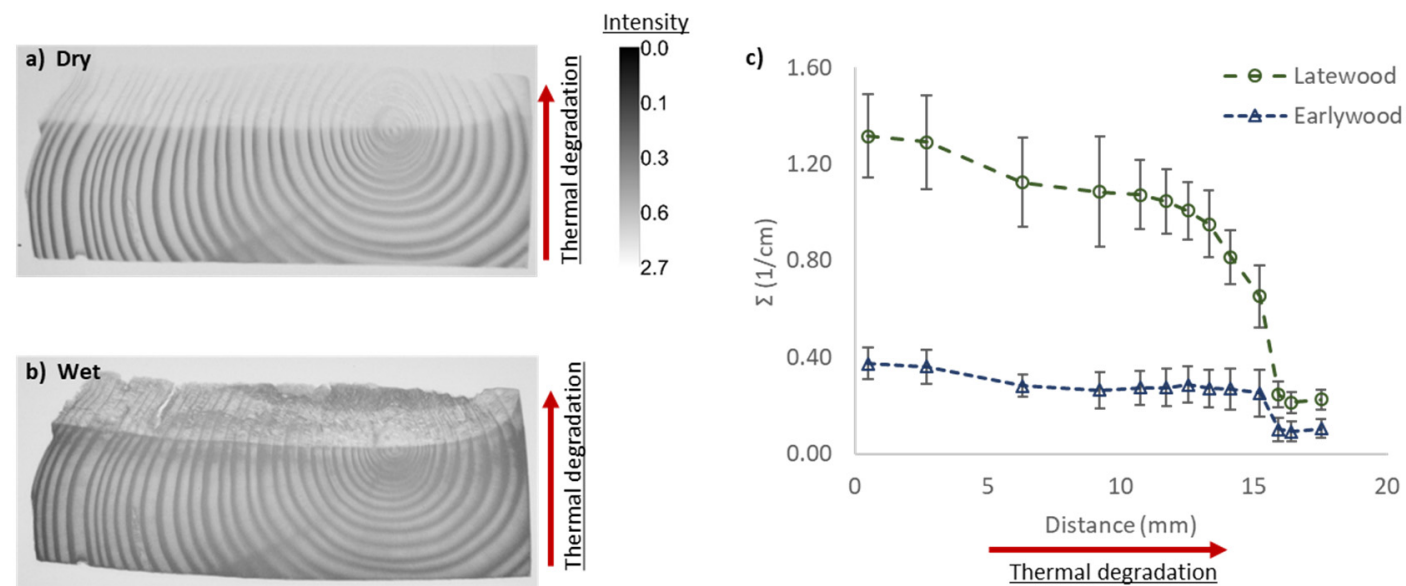

Figure 3. Digitized neutron radiographs obtained from a thermally degraded sample imaged (a) dry and (b) wet. (c) Plot showing the effects of thermal degradation on the average attenuation coefficients calculated from the dry sample shown in (a).

\section{Conclusions}

Thermal neutrons produced by a compact source were used to image various forest products. Using this tool, we investigated the combined effects of acetylation and moisture uptake on wood blocks and WPCs. We also investigated the effects of thermal degradation on a wood sample. Increasing the moisture content of the samples led to reduced contrast between the earlywood and latewood bands in both unmodified and acetylated wood samples. However, for the thermally degraded sample increasing the moisture content led to improved contrast that revealed new features and defects in the degraded regions. Our results show that the enhanced hydrogen sensitivity of the technique makes it 
ideal to study the effects of degradation in wood and other forest products, particularly, in terms of local variations in the material's density or its hydrogen content.

Author Contributions: N.Z.P. conceived the paper, designed the experiments and analyzed the radiographs. M.T. collected the radiographs at the imaging center and digitized them. L.H. and R.E.I. prepared the samples. N.Z.P. wrote the paper with contributions from all authors. All authors have read and agreed to the published version of the manuscript.

Funding: This research received no external funding.

Institutional Review Board Statement: Not applicable.

Informed Consent Statement: Not applicable.

Data Availability Statement: Data available upon request to the corresponding author.

Acknowledgments: This research used one of the thermal neutron radiography beamlines at the Phoenix Neutron Imaging Center (PNIC) in Fitchburg, WI.

Conflicts of Interest: The authors declare no conflict of interest.

\section{References}

1. Jakes, J.E.; Arzola, X.; Bergman, R.; Ciesielski, P.; Hunt, C.G.; Rahbar, N.; Tshabalala, M.; Wiedenhoeft, A.C.; Zelinka, S.L. Not Just Lumber-Using Wood in the Sustainable Future of Materials, Chemicals, and Fuels. JOM 2016, 68, 2395-2404, doi:10.1007/s11837-016-2026-7.

2. $\quad$ Langan, P.; Evans, B.R.; Foston, M.; Heller, W.T.; O'Neill, H.; Petridis, L.; Pingali, S.V.; Ragauskas, A.J.; Smith, J.C.; Urban, V.S.; et al. Neutron Technologies for Bioenergy Research. Ind. Biotechnol. 2012, 8, 209-216, doi:10.1089/ind.2012.0012.

3. Kardjilov, N.; Festa, G. (Eds.) Neutron Methods for Archaeology and Cultural Heritage; Part of the Neutron Scattering Applications and Techniques Book Series; Springer International Publishing: Cham, Switzerland, 2017; ISBN 978-3-319-33161-4, doi:10.1007/978-3-319-33163-8.

4. Odin, G.P.; Rouchon, V.; Ott, F.; Malikova, N.; Levitz, P.; Michot, L.J. Neutron imaging investigation of fossil woods: Nondestructive characterization of microstructure and detection of in situ changes as occurring in museum cabinets. Foss. Rec. 2017, 20, 95-103, doi:10.5194/fr-20-95-2017.

5. Sonderegger, W.; Hering, S.; Mannes, D.; Vontobel, P.; Lehmann, E.; Niemz, P. Quantitative determination of bound water diffusion in multilayer boards by means of neutron imaging. Eur. J. Wood Wood Prod. 2010, 68, 341-350, doi:10.1007/s00107-0100463-5.

6. Sonderegger, W.; Glaunsinger, M.; Mannes, D.; Volkmer, T.; Niemz, P. Investigations into the influence of two different wood coatings on water diffusion determined by means of neutron imaging. Eur. J. Wood Wood Prod. 2015, 73, 793-799, doi:10.1007/s00107-015-0951-8.

7. Lanvermann, C.; Sanabria, S.J.; Mannes, D.; Niemz, P. Combination of neutron imaging (NI) and digital image correlation (DIC) to determine intra-ring moisture variation in Norway spruce. Holzforschung 2014, 68, 113-122, doi:10.1515/hf-2012-0171.

8. Sedighi Gilani, M.; Abbasion, S.; Lehmann, E.; Carmeliet, J.; Derome, D. Neutron imaging of moisture displacement due to steep temperature gradients in hardwood. Int. J. Therm. Sci. 2014, 81, 1-12, doi:10.1016/j.ijthermalsci.2014.02.006.

9. Islam, M.N.; Khan, M.A.; Alam, M.K.; Zaman, M.A.; Matsubayashi, M. Study of water absorption behavior in wood plastic composites by using neutron radiography techniques. Polym. Plast. Technol. Eng. 2003, 42, 925-934, doi:10.1081/PPT-120025004.

10. Mannes, D.; Lehmann, E.; Cherubini, P.; Niemz, P. Neutron imaging versus standard X-ray densitometry as method to measure tree-ring wood density. Trees Struct. Funct. 2007, 21, 605-612, doi:10.1007/s00468-007-0149-8.

11. Sonderegger, W.; Mannes, D.; Kaestner, A.; Hovind, J.; Lehmann, E. On-line monitoring of hygroscopicity and dimensional changes of wood during thermal modification by means of neutron imaging methods. Holzforschung 2015, 69, 87-95, doi:10.1515/hf-2014-0008.

12. Ossler, F.; Santodonato, L.J.; Warren, J.M.; Finney, C.E.A.; Bilheux, J.C.; Mills, R.A.; Skorpenske, H.D.; Bilheux, H.Z. In situ monitoring of hydrogen loss during pyrolysis of wood by neutron imaging. Proc. Combust. Inst. 2019, 37, 1273-1280, doi:10.1016/j.proci.2018.07.051.

13. Goldstein, I.S.; Jeroski, E.B.; Lund, A.E.; Nielson, J.F.; Weater, J.M. Acetylation of Wood in Lumber Thickness. For. Prod. J. 1961, 11, 363-370.

14. Ibach, R.E.; Clemons, C.M.; Schumann, R.L. WPCs with Reduced Moisture: Effects of Chemical Modification on Durability in the Laboratory and Field. In Proceedings of the 9th International Conference on Woodfiber-Plastic Composites, Madison, WI, USA, 21-23 May 2007; pp. 259-266.

15. Ibach, R.E.; Rowell, R.M.; Lee, B.-G. Decay Protection Based on Moisture Exclusion Resulting From Chemical Modification of Wood. In Proceedings of the 5th Pacific Rim Bio-Based Composites Symposium, Canberra, Australia, 10-13 December 2000; pp. 197-204. 
16. Rasband, W.S.; ImageJ, U.S. National Institutes of Health, Bethesda, Maryland, USA. 1997-2018. Available online: https://imagej.nih.gov/ij/ (accessed on 5 November 2020).

17. Schindelin, J.; Arganda-Carreras, I.; Frise, E.; Kaynig, V.; Longair, M.; Pietzsch, T.; Preibisch, S.; Rueden, C.; Saalfeld, S.; Schmid, B.; et al. Fiji: An open-source platform for biological-image analysis. Nat. Methods 2012, 9, 676-682, doi:10.1038/nmeth.2019.

18. Mori, M.; Kuhara, S.; Kobayashi, K.; Suzuki, S.; Yamada, M.; Senoo, A. Non-destructive tree-ring measurements using a clinical 3T-MRI for archaeology. Dendrochronologia 2019, 57, 125630, doi:10.1016/j.dendro.2019.125630.

19. Carminati, C.; Boillat, P.; Schmid, F.; Vontobel, P.; Hovind, J.; Morgano, M.; Raventos, M.; Siegwart, M.; Mannes, D.; Gruenzweig, C.; et al. Implementation and assessment of the black body bias correction in quantitative neutron imaging. PLoS ONE 2019, 14, e0210300, doi:10.1371/journal.pone.0210300.

20. Gnatowski, M.; Ibach, R.; Leung, M.; Sun, G. Magnetic resonance imaging used for the evaluation of water presence in wood plastic composite boards exposed to exterior conditions. Wood Mater. Sci. Eng. 2015, 10, 94-111, doi:10.1080/17480272.2014.920418 